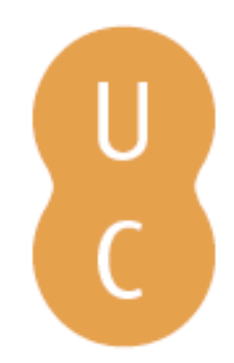

\title{
nommalina
}

\section{As redes sociais atuando na construção de bibliotecas virtuais na área da saúde}

Autor(es): $\quad$ Santos, Paula Xavier dos; Henning, Patrícia Corrêa

Publicado por: Imprensa da Universidade de Coimbra

URL

persistente: URI:http://hdl.handle.net/10316.2/31945

DOI: $\quad$ DOI:http://dx.doi.org/10.14195/978-989-26-0869-3_33

Accessed : $\quad$ 26-Apr-2023 11:32:02

A navegação consulta e descarregamento dos títulos inseridos nas Bibliotecas Digitais UC Digitalis, UC Pombalina e UC Impactum, pressupõem a aceitação plena e sem reservas dos Termos e Condições de Uso destas Bibliotecas Digitais, disponíveis em https://digitalis.uc.pt/pt-pt/termos.

Conforme exposto nos referidos Termos e Condições de Uso, o descarregamento de títulos de acesso restrito requer uma licença válida de autorização devendo o utilizador aceder ao(s) documento(s) a partir de um endereço de IP da instituição detentora da supramencionada licença.

Ao utilizador é apenas permitido o descarregamento para uso pessoal, pelo que o emprego do(s) título(s) descarregado(s) para outro fim, designadamente comercial, carece de autorização do respetivo autor ou editor da obra.

Na medida em que todas as obras da UC Digitalis se encontram protegidas pelo Código do Direito de Autor e Direitos Conexos e demais legislação aplicável, toda a cópia, parcial ou total, deste documento, nos casos em que é legalmente admitida, deverá conter ou fazer-se acompanhar por este aviso. 
Maria Manuel Borges

Elias Sanz Casado

Coordenação

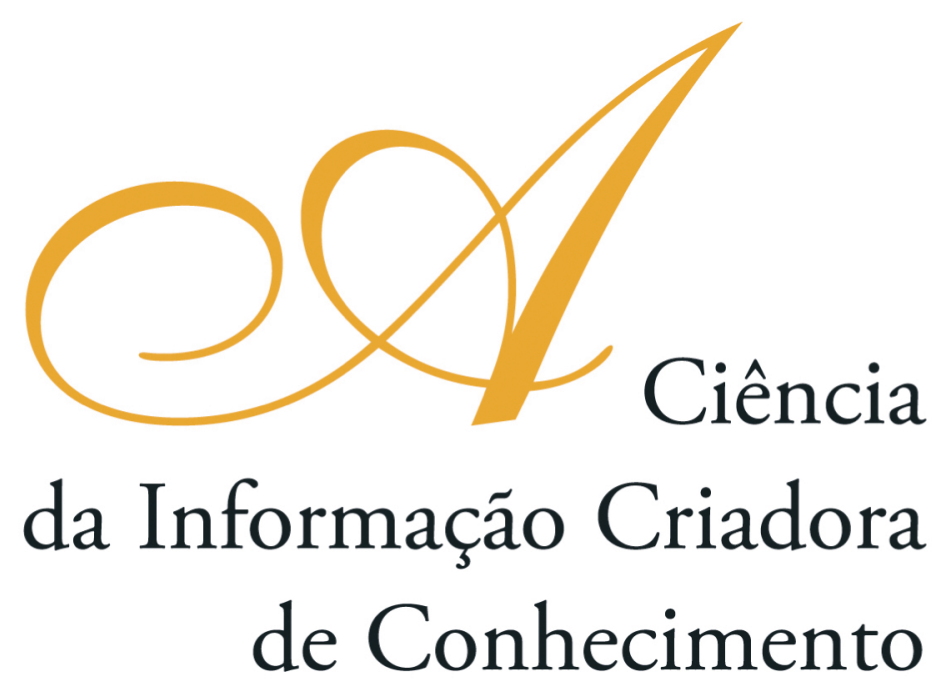

Vol. I I

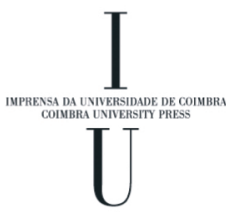

- COImbra 2009 


\title{
As Redes Sociais atuando na construçấo de Bibliotecas Virtuais
} NA ÁREA da SAÚde

\author{
Paula Xavier dos Santos \\ Casa de Oswaldo Cruz, FioCruz (Brasil) \\ Patrícia Corrêa Henning \\ Universidade Federal do Estado do Rio de Janeiro (Brasil)
}

\section{Introdução}

O conceito de redes pode ser tratado por diferentes dimensóes: a rede enquanto suporte físico e que, portanto, possui uma realidade material e, a rede enquanto característica da dinâmica de relações entre grupos, poder, informação, espaço e tempo e que, portanto, se comporta como entidade abstrata. A dinâmica do trabalho em rede vem se consolidando, há pelo menos três décadas, como modelo de gestão cooperativa para o compartilhamento da informação e do conhecimento, adotado por indivíduos e instituiçóes. Este pôster apresenta a experiência da Casa de Oswaldo Cruz/FIOCRUZ na construção e desenvolvimento da Rede da Biblioteca Virtual em Saúde - História e Patrimônio Cultural da Saúde (BVS HPCS), definida como uma instância de convergência para a promoção, organização e realização da cooperação técnica entre Instituiçóes da América Latina e Caribe, podendo chegar aos países de língua portuguesa, que atuam na área da História e do Patrimônio Cultural da Saúde. O modelo Biblioteca Virtual em Saúde foi desenvolvido pelo Centro Latino-Americano e do Caribe de Informação em Ciências da Saúde - BIREME e contempla três dimensóes: as Redes sociais, de Conteúdos e de Ambientes Aprendizes, resultando em um híbrido que faz convergir estas diferentes dimensóes numa única rede.

\section{Objetivos e Metodologia}

Os objetivos gerais deste trabalho são: apresentar a metodologia de Biblioteca Virtual em Saúde - BVS, criada pela BIREME; relatar a experiência da Casa de Oswaldo Cruz - COC na utilização do modelo BVS na construção da Rede BVS HPCS e apresentar a BVS HPCS e sua Comunidade Virtual. O modelo BVS contempla a Rede social formada por instituiçôes e indivíduos que atuam como produtores, intermediários e usuários de informação científica e técnica em saúde. A Rede de conteúdos, construída coletivamente pela rede social, é constituída pelas fontes e fluxos de informação expressos nas coleçóes de produtos, serviços e eventos de informaçáo, que se conformam como bens públicos. E os Ambientes Aprendizes são aqueles em que possibilitam o intercâmbio de informaçáo, experiências e conhecimento tácito em espaços colaborativos on line, como por exemplo, a comunidade virtual, com o objetivo de maximizar as 
relaçóes entre a rede social e a rede de conteúdos. A Casa de Oswaldo Cruz/FIOCRUZ lançou, em setembro de 2008, no âmbito do $8^{\circ}$. Congresso Regional de Informação em Ciência da Saúde - CRICS8 a Biblioteca Virtual em Saúde - História e Patrimônio Cultural da Saúde - BVS HPCS. Contempla todas as dimensōes do modelo BVS (rede social, de conteúdos e ambientes aprendizes) sem privilegiar nenhuma delas. A BVS HPCS foi baseado na gestão compartilhada de fontes e fluxos de informação e conhecimento tratados como bens públicos e operadas em rede na web com acesso aberto e universal que visam aumentar a visibilidade e os usos sociais do conhecimento científico, técnico e factual em história e patrimônio cultural da saúde. Esta biblioteca tem por objetivos utilizar o modelo BVS de trabalho cooperativo contribuindo para o fortalecimento da História e do Patrimônio Cultural da Saúde como parte integral dos sistemas nacionais de saúde, visando valorizar a identidade e a memória e ainda contribuir para a consciência da sociedade sobre a importância do patrimônio históricoarquitetônico, museológico, científico, artístico e documental. Está voltada para o trabalho coletivo e o compartilhamento de informaçóes e experiências nacionais na identificação, recuperação, conservação, investigação, valorização e disseminação da Historia e Patrimônio Cultural da Saúde.

\section{Resultados}

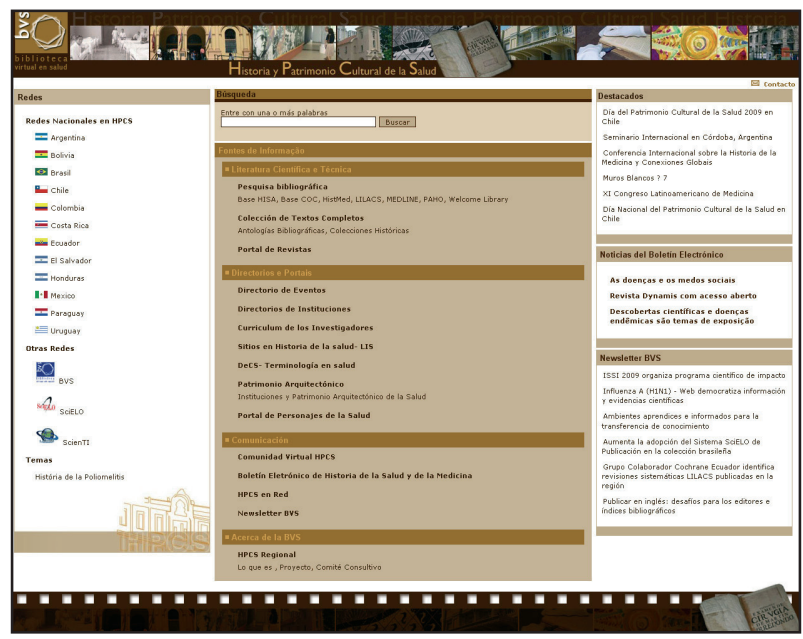

Fig. 1 - FBVS HPCS

http://hpcs.bvsalud.org/

A Rede Social é composta por 12 países da América Latina e Caribe que compreende: Argentina, Bolívia, Brasil, Chile, Colômbia, Costa Rica, Equador, El Salvador, Honduras, México, Paraguai e Uruguai. A Rede de Conteúdos está contemplada pelas fontes de informação: Instituiçóes e Patrimônio Arquitetônico da Saúde; Localizador de Informaçóes em Saúde - LIS; Coleçóes Históricas; Antologias Bibliográficas; Portal de Revistas; Portal de Personagens da Saúde; Diretório de Instituiçóes e Diretório de Eventos. 


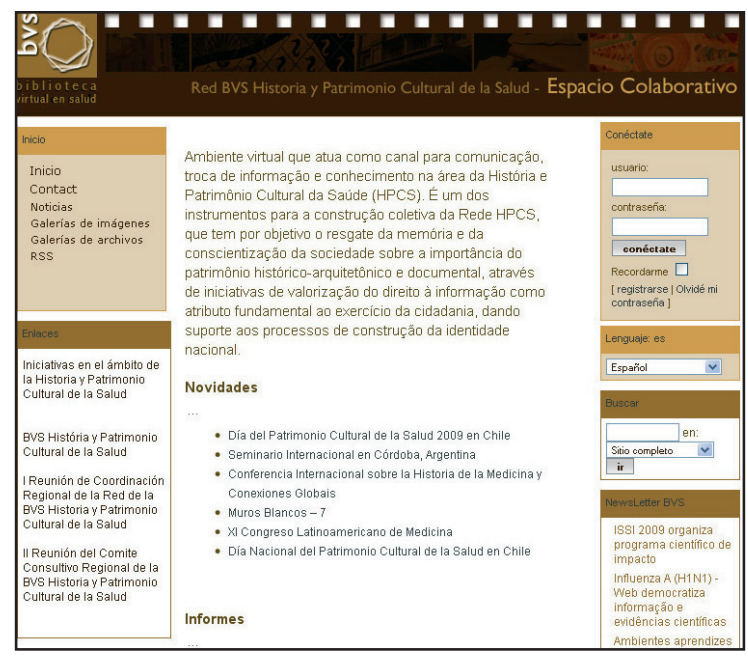

Fig. 2 - Espaço Colaborativo

http://cv-hpcs.bvs.br

A dimensão dos Ambientes Aprendizes foi fortalecida pela criação do "Espaço Colaborativo da Rede HPCS". Este ambiente atua como uma plataforma para a comunicação, intercâmbio de informação e conhecimento na área de História e Patrimônio Cultural da Saúde. É uma Comunidade Virtual composta de várias ferramentas baseadas no conceito de web 2.0 colaborativa, que facilita a comunicação e o trabalho conjunto entre seus participantes. É considerada um instrumento facilitador da construção coletiva do conhecimento em HPCS. 